\title{
Constitució i altar: la fiscalització del comportament del clergat per part del cap polític durant el Trienni Liberal (1820-1823)
}

Xavier Sànchez Sancho

021194xavi@gmail.com Arxiu Històric Arxidiocesà de Tarragona

Carrer de Sant Pau, 2

43003 Tarragona

Resum: El cap polític com a màxima autoritat civil va ser conscient des d'un bon inici del Trienni Liberal (1820-1823) que s'havien de controlar els comportaments que tenien a l'altar els clergues de l'arquebisbat de Tarragona. El sacerdot, com a guia espiritual, a través dels seus actes incidia sobre l'opinió pública d'una manera que ni les societats patriòtiques, ni cap espai de confluència social d'activitat política, podia fer-ho. Ens trobem amb una estructura eclesiàstica generalment reticent a acceptar el liberalisme, on la gran majoria de clergues desoïa les ordres de promocionar el constitucionalisme des de l'altar. En aquesta recerca s'explicarà que a mesura que la tensió social i la desobediència clerical van anar creixent, hi va haver una major imposició del cap polític sobre l'arquebisbat de Tarragona.

Paraules clau: Església, cap polític, zelador eclesiàstic, Trienni Liberal, vicaris generals, Constitució, arquebisbat de Tarragona.

Constitution and altar: control of the clergy's behaviour

by the political leader during the Liberal Triennium (1820-1823)

АвsтRAст: The political leader, as the highest civil authority, representing the executive power, was aware from the beginning of the Liberal Triennium that the behaviour of the priests of the archbishopric of Tarragona had to be monitored. Priests, as the spiritual guides and pastors of parishioners, had significant influence on public opinion through their actions,

SÁnchez SAnCho, Xavier, «Constitució i altar: la fiscalització del comportament del clergat per part del cap polític durant el Trienni Liberal (1820-1823)». Cercles. Revista d'Història Cultural, 23, 57-79. ISSN: 1139-0158. ISSN-e: 1699-7468. DOI: 10.1344/cercles2020.23.1010. Data de recepció: 18/2/2020. Data d'acceptació: 3/6/2020. 
even more so than patriotic societies or spaces of social and politic confluence. This was an ecclesiastic structure generally reluctant to accept liberalism, where most priests would not hear of promoting constitutionalism from the altar. This research shows that as social tensions and clerical disobedience increased, there was greater pressure from the political leader upon the archbishopric of Tarragona.

Keywords: Church, political leader, ecclesiastical member, Liberal Triennium, vicar general, constitution, Archbishopric of Tarragona.

\section{Introducció}

El cap polític, com a màxima autoritat civil i representant del poder executiu, va ser conscient des d'un bon inici del Trienni que s'havia de controlar l'estructura eclesiàstica per assegurar una opinió pública favorable. Les esglésies foren uns dels majors espais de confluència pública. La religió catòlica tingué una presència molt important en aquella societat de principis del segle XIx. Les opinions difoses pel rector del poble tenien un pes considerable sobre els assistents de la missa. A més, tenia la capacitat de ser present a totes les poblacions del regne. En una correspondència del cap polític als vicaris generals de l'arquebisbat, aquest els deia: «V.S.S. conocen cuanto influye en la opinión de los pueblos el ejemplo de los párrocos [...]». ${ }^{\mathrm{I}}$ Per aquest motiu, acabada de proclamar la Constitució l'any I820, el cap polític va ordenar jurar la Constitució al clergat. També va ordenar l'obligatorietat de promocionar aquest text constitucional des de l'altar. Ho van fer també perquè era conscient que molts sectors del clergat no estaven disposats a ajudar a difondre la Constitució. En la

I Arxiu Històric Arxidiocesà de Tarragona (AHAT), Fons Secretaria de Cambra i Govern, «Registres», subsèrie «Oficis del general intendent i cap polític» (I8I9-I823), n. 9, f. I34r.

Cercles. Revista d'Història Cultural, 23 (2020), 57-79.

ISSN: 1139-0158. e-ISSN: 1699-7468. DOI: 10.1344/cercles2020.23.1010. 
passada experiència constitucional de l'any I8I2 van veure com molts sectors eclesiàstics van oposar-s'hi fermament. En aquesta recerca veurem quins foren els esforços del cap polític per fiscalitzar el comportament del clergat, com ho va fer i quina profunditat de control va tenir sobre l'estructura eclesiàstica. Per primera vegada hi ha una anàlisi del control que va tenir el poder civil sobre l'Església durant el Trienni. I aportem fonts documentals inèdites que desvelen la difícil relació que es va generar entre aquests poders.

\section{Estat de la qüestió}

Són moltes i variades les recerques fetes sobre el Trienni Liberal. Ens interessa compartir les que, d'una banda, estudiïn l'etapa liberal des de les institucions catòliques catalanes i, després, també les que facin un estudi sòlid sobre els caps polítics i les diputacions provincials.

Un dels primers estudis que trobem en aquest sentit en la historiografia eclesiàstica és l'obra de Feliu de Montfort. ${ }^{2}$ La recerca se centra en els corrents ideològics i els esdeveniments que marcaren el clericat català durant el Trienni. Analitzarem amb molta exactitud les tesis i els corrents ideològics que hi havia dintre d'aquest cos eclesiàstic. Cal dir que l'obra de Montfort no està centrada en cap diòcesi concreta, sinó que analitza tot el territori català. Tampoc no analitza la influència del cap polític sobre l'estructura eclesiàstica, però sí que ens ajuda a veure que el cos eclesiàstic no pensava i actuava de manera homogènia, sinó que dintre del clergat hi havia corrents diversos. Alhora, també ens ajuda a reflexionar com, en funció del període en què succeeix, sempre hi ha imposició d'unes ideologies sobre unes altres.

2 Gaspar Feliu Montfort, La clerecia catalana durant el Trienni Liberal, Barcelona, Institut d'Estudis Catalans, I972.

Cercles. Revista d'Història Cultural, 23 (2020), 57-79. ISSN: 1139-0158. e-ISSN: 1699-7468. DOI: 10.1344/cercles2020.23.1010. 
Després, també tenim l'estudi de Puigvert i Solà. ${ }^{3}$ Larticle ens permet entendre la xarxa parroquial que hi havia. Com bé esmenta l'autor en la recerca, «Aquesta implantació territorial i capilllar de la parròquia podia resultar útil tant a la monarquia, a les autoritats municipals com als cobradors del delme, al marge, és clar, de les seves finalitats pastorals i religioses». La xarxa parroquial va tenir molta importància i en aquest mateix estudi també ho veurem. Entendre els motius que van tenir els liberals per controlar l'Església és clau per entendre el període, i l'obra de Puigvert ho tracta molt professionalment.

També cal referenciar el treball que fa Joan Bada. ${ }^{4}$ Centrat en el bisbat de Barcelona, cal fixar-se en la secció que explica la successió del pontificat del bisbe Sichar i les disputes polítiques que hi va haver per ocupar la cadira de bisbe durant el Trienni Liberal. L'estudi exhaustiu i detallat de Bada no narra la influència del cap polític sobre la diòcesi de Barcelona, però sí que plasma aquesta situació de confluència d'interessos. El que passava dintre del món eclesiàstic també interessava al món polític. De la mateixa manera que hi va haver un interès especial a situar bisbes de caire liberal a les diòcesis, també es va intentar apartar tots els bisbes que eren obertament absolutistes. Per aquest motiu, a Tarragona, Jaume Creus i Martí no va poder accedir al títol d'arquebisbe durant tot el Trienni. El treball de

3 Joaquim M. Puigvert i SolÀ, «Església i territori en els orígens de la Catalunya contemporània», Treballs de la Societat Catalana de Geografia, n. 44, 1997, pp. 85-III.

4 Joan BADA, L'Església de Barcelona en la crisi de l'Antic Règim (1808-1833), Barcelona, Edicions de la Facultat de Teologia de Barcelona, 1986.

5 Jaume Creus i Martí (Mataró, I760 - Tarragona, I825), important polític i religiós, fou diputat a les Corts de Cadis i president d'aquestes el 24 d'abril de i8II. Fou un rellevant defensor de l'absolutisme. Fou bisbe de Menorca i va ser nomenat arquebisbe de Tarragona el I820. Però les noves autoritats del Trienni Liberal, a partir de les denúncies formulades per l'Ajuntament de Reus, s'oposaren al seu nomenament, ja que era l'exponent de l'actitud contrarevolucionària del clergat. No va ser fins el I824 que va poder accedir a la mitra de Tarragona. Durant l'època del Trienni estigué exiliat a la regència d'Urgell.

Cercles. Revista d'Història Cultural, 23 (2020), 57-79.

ISSN: 1139-0158. e-ISSN: 1699-7468. DOI: 10.1344/cercles2020.23.1010. 
Ramon Salas i Oliveras ${ }^{6}$ explica molt detalladament la biografia de Creus, figura força debatuda històricament i molt interessant de llegir i analitzar. A la diòcesi de Vic també és molt rellevant analitzar la figura del bisbe Raimon Strauch. Una de les obres més completes és la biografia feta per Jordi Figuerola. Com veiem a l'obra de Figuerola, Strauch mantingué una postura molt ferma davant l'absolutisme. ${ }^{7}$ El pensament del bisbe va incomodar tant, que fou assassinat el I6 d'abril de I823, ${ }^{8}$ en un moment en què el clímax de la tensió bèllica era molt alt. Jordi Roca relata en la seva tesi fil per randa com succeí aquest esdeveniment. A Tortosa també tenim l'estudi de Joan R. Vinaixa, que narra algunes de les actuacions del bisbe Manuel Ros de Medrano. ' L'obra de Vinaixa no s'enfoca a analitzar concretament el paper del clergat tortosí, sinó que la seva línia d'estudi és genèrica, atès que cerca els esdeveniments ocorreguts a tot el partit de Tortosa. Finalment, a la diòcesi de Lleida tenim Antoni Sánchez Carcelén. ${ }^{10}$ Aquest és l'historiador que més treballa sobre la qüestió eclesiàstica durant el Trienni a la diòcesi lleidatana. L'historiador narra que Simón Renteria i Reyes, bisbe absolutista, fou expulsat per les seves idees conservadores i tradicionalistes. En una altra recerca ${ }^{\text {II }}$ explica també les repressions d'algunes autoritats liberals sobre l'Església de Lleida i que la instauració del règim liberal va tenir una repercussió sobre el pontificat de Renteria i el clergat lleidatà.

6 Ramon Salas Oliveras, Biografia de l'Excm. i Rvdm. Dr. D. Jaume Creus i Martí, Mataró, Caixa d'Estalvis i Mont de Pietat de Mataró, I96I.

7 Jordi Figuerola, Església i societat a principis del segle XIX, Vic, Eumo, I988, p. II5.

8 Jordi Roca, La Barcelona revolucionària i liberal: exaltats, milicians i conspiradors, Barcelona, Fundació Noguera, 20II, pp. 166-167.

9 Joan R. Vinaixa i Miró, El Trienni Constitucional al partit de Tortosa (18201823): Aproximació històrica, Valls, Cossetània, 2003.

io Antoni SÁnchez Carcelén, Absolutisme i liberalisme. L'Església de Lleida durant el regant de Ferran VII, la Pobla de Claramunt, Ajuntament de la Pobla de Claramunt, 2012.

ir Antoni Sánchez Carcelén, «La repercusión del régimen constitucional en la Iglesia de Lleida durante el trienio liberal», Hispania Sacra, vol. 59, n. I19, 2007, pp. 323-336. 
D'altra banda, cal destacar la tesi doctoral de Maria Antònia Ferrer i Bosch. ${ }^{12}$ La seva recerca és fins al moment l'estudi més complet d'anàlisi de l'etapa del Trienni Liberal a la ciutat de Tarragona. L'obra de Ferrer i Bosch se centra sobretot en l'anàlisi de les actuacions dels poders civils i ho fa d'una manera més superficial sobre el clergat tarragoní, si bé analitza els fet succeïts a la catedral i, d'una manera més genèrica, a tot l'arquebisbat. En cap cas s'analitzen les relacions del cap polític i l'arquebisbat. Posteriorment a la seva recerca doctoral va redactar l'article ${ }^{\mathrm{r}} \mathrm{en}$ què ampliava l'anàlisi ideològica del clergat tarragoní. En aquest article la historiadora analitza els membres del clergat que van desenvolupar una ideologia liberal i que foren reprimits sota el pontificat de l'arquebisbe Creus en la seva arribada l'any I824. També sobre aquesta temàtica tenim un article de Pere Anguera. ${ }^{14}$ En aquest cas, l'historiador reusenc fa una "classificació» ideològica d'alguns clergues. I classifica no solament alguns clergues liberals, sinó també els absolutistes.

El càrrec del cap polític tingué una gran preponderància durant tota l'etapa del Trienni. Com a delegat governatiu i president de les diputacions, s'encarregava, a més a més de la nova distribució territorial de les províncies, d'assegurar i defensar el sistema constitucional. Pel que fa a la bibliografia, cal destacar el treball fet per Ramon Arnabat. Primerament, amb la recerca iniciada en la seva tesi docto$\mathrm{ral}^{15} \mathrm{i}$, després, amb la recerca en què analitza la revolució de 1820 i

I2 Maria Antònia Ferrer Bosch, La ciutat de Tarragona durant el Trienni Liberal: 1820-1823, Barcelona, Universitat de Barcelona, 1976.

I3 Maria Antònia Ferrer Bosch, «Una rèplica al període liberal: Jaume Creus arquebisbe de Tarragona i president de la Junta de Fe (I823-I825)", Quaderns d'Història Contemporània, n. 6, 1984, pp. 7-18.

I4 Pere Anguera, «La ideologia del clergat tarragoní a la crisi de l'antic règim», Anuari 1990-I99I de la Societat d'Estudis d'Història Eclesiàstica, Moderna i Contemporània de Catalunya 1992, pp. 9I-I49.

I5 Ramon Arnabat Mata, Revolució i contrarevolució a Catalunya durant el Trienni Liberal (I820-I823), Barcelona, Universitat Pompeu Fabra, I999.

Cercles. Revista d'Història Cultural, 23 (2020), 57-79.

ISSN: 1139-0158. e-ISSN: 1699-7468. DOI: 10.1344/cercles2020.23.1010. 
tot el període del Trienni. ${ }^{16}$ L'historiador penedesenc fa l' exercici de descriure què era el cap polític i quines tasques feia i també situa ideològicament els cap polítics de Catalunya. Després també hem de destacar la feina feta per Josep Sarrión Gualda. Primerament, pel seu llibre sobre la història de la Diputació Provincial de Catalunya ${ }^{17}$ i, després, també pel seu treball sobre l'organització política del pla de Barcelona durant el règim constitucional. ${ }^{18}$ Mitjançant el treball fet per Sarrión podem veure clarament que el cap polític tenia un paper protagonista en totes les decisions polítiques, ja que aquest càrrec era el màxim responsable territorial del govern liberal. ${ }^{19}$ En definitiva, la creació del càrrec del cap polític va permetre als liberals poder controlar i defensar el règim constitucional amb més proximitat al territori. Finalment, també cal afegir el treball de Manel Risques, ${ }^{20}$ autor que, enfocant-ho dintre del territori barceloní, també tracta la gestió del govern civil durant el període del Trienni.

La bibliografia que tracta el Trienni Liberal és molt variada, ja sigui des d'un enfocament historiogràfic eclesiàstic, ja sigui des d'un enfocament civil. Però dintre de la bibliografia tenim un buit historiogràfic, ja que no s'analitza la relació entre aquests dos poders. És a dir, encara no hi ha un estudi que busqui cercar i entendre quin tipus de relació hi havia entre el cap polític i l'Església. En aquest article

i6 Ramon Arnabat Mata, La revolució de i8zo i el Trienni Liberal a Catalunya, Barcelona, Eumo, 200I.

I7 Josep Sarrión Gualda, La Diputació provincial de Catalunya sota la Constitució de Cadis, I8I2-I8I4 i I820-I822, Barcelona, Generalitat de Catalunya, Departament de Governació, I99I.

I8 Josep Sarrión Gualda, «L'organització política del Pla de Barcelona abans de I854. El règim constitucional», Quaderns del Seminari d'Història de Barcelona, octubre 2000, pp. 3-56.

I9 Cal recordar que en un primer moment el càrrec de cap polític era genèric a tot Catalunya, però durant el desenvolupament del Trienni es creà un càrrec de cap polític per a cada província.

20 Manel Risques, El Govern Civil de Barcelona al segle XIX, Barcelona, PAM, I995.

Cercles. Revista d'Història Cultural, 23 (2020), 57-79. ISSN: 1139-0158. e-ISSN: 1699-7468. DOI: 10.1344/cercles2020.23.1010. 
s'analitza el nivell de control que va intentar aplicar el cap polític sobre l'arquebisbat de Tarragona. És, doncs, un primer intent d'emplenar aquest buit. La tasca es realitza a partir del tractament minuciós de tota la correspondència que hi va haver entre el cap polític i els vicaris generals ${ }^{21}$ de l'arxidiòcesi durant el període, documentació que és preservada íntegrament a l'Arxiu Històric Arxidiocesà de Tarragona. $^{22}$

\section{Una radiografia ideològica del clergat de l'arxidiòcesi de Tarragona}

Seria un error concebre l'estructura de l'Església, ideològicament parlant, de manera homogènia. Molts cops s'entén l'Església del segle XIX com un cos que era partidari completament de la conservació de les estructures de l'Antic Règim. Però el clergat no és quelcom aillat de la societat: cada clergue va tenir la seva visió de la realitat i hi va haver diferents posicionaments. Per tant, es vol remarcar que no tot el clergat de l'arxidiòcesi de Tarragona fou absolutista. De fet, tenim exemples de clergues, com és el cas del prevere Tomàs Pedrol, ${ }^{23}$

2I Parlem de la importància del càrrec de vicari general durant el Trienni perquè l'arquebisbe Jaume Creus i Martí, nomenat el I820, no va poder entrar a Tarragona fins que no va finalitzar el Trienni, és a dir, ja el I824. Per tant, la gestió interna de l'arquebisbat de Tarragona durant el Trienni Liberal fou executada pels vicaris generals; concretament, estaven al capdavant de l'arquebisbat Bonaventura Marès i Manuel Llopis.

22 AHAT, Fons Secretaria de Cambra i Govern, «Registres», subsèrie «Oficis del general intendent i el cap polític» (1819-1823), n. 9.

23 Tomàs Pedrol fou el rector de la parròquia de Maspujols durant el Trienni Liberal. Aquest clergue va fer un seguit de discursos excepcionals, en els quals defensava molt fermament el liberalisme i els avenços que s'havien de produir en el país. Aquest rector, un cop va finalitzar l'etapa liberal, fou reprimit a causa del posicionament ideològic manifest en aquests discursos. Seria interessant poder iniciar en el futur algunes investigacions centrades en aquest personatge, cosa que permetria ampliar els noms que apareixen en l'article de Maria Antònia Ferrer Bosch, «Una rèplica al període liberal», pp. 7-I8.

Cercles. Revista d'Història Cultural, 23 (2020), 57-79.

ISSN: 1139-0158. e-ISSN: 1699-7468. DOI: 10.1344/cercles2020.23.1010. 
i d'altres clergues regulars i seculars, que tingueren un paper important en la difusió i la defensa de la ideologia liberal. Però sí que és cert que mitjançant algunes accions concretes podem establir una ideologia dominant. Això, ho podrem analitzar gràcies a la documentació referent als juraments de la Constitució per part del clergat i la correspondència entre el cap polític i els vicaris generals.

Un cop proclamada la Constitució, el març de I820, comencen a arribar oficis del cap polític adreçats als vicaris generals. En aquesta correspondència s'ordenava que els clergues juressin la Constitució. La concepció del jurament assegurava vincular el clergat al nou sistema $\mathrm{i}$, des d'aquest punt de vista, des d'un principi el poder liberal va començar a fiscalitzar el comportament del clergat. Cal pensar que desoir una ordre del cap polític comportava l'incompliment d'una llei, i això tenia conseqüències per al clergue desobedient. La primera correspondència que hi ha entre el govern superior polític de Catalunya i l'arquebisbat de Tarragona és del I7 de març de i820. El cap polític, Josep de Castellar y Lladó, ${ }^{24}$ explica als vicaris que:

Al jurar Su Majestad y la Nación la Constitución política de la Monarquía, parece que la Providencia se digna llamar a todos los súbditos de Su Majestad a un punto de unidad para alejar la división y los desastres que amenazaban a la patria [...].

Continua explicant que, tot i que hi ha hagut conflictes entre l'Església i l'Estat, i moltes d'aquestes llagues ja han cicatritzat,

24 Fou el primer cap polític de Catalunya del Trienni. Va ser nomenat el ıo de març i ratificat per la Junta Suprema el 28 del mateix mes. Fou un polític liberal moderat. A finals d'any va passar a ocupar el càrrec de cap polític de València. Ramon Arnabat Mata, Revolució $i$ contrarevolució a Catalunya, p. 206. 
No dexa de haber sujetos o poco ilustrados o seducidos que difunden especies contrarias al orden y a los principios de fraternidad y unión que deben estrechar ahora más que nunca a los que tenemos la gloria de ser hijos de la Patria y de la Yglesia. ${ }^{25}$

Finalment, Josep Castellar li diu que

Es muy urgente el que prevenga V.S. a todos los respetables individuos del clero secular y regular de esta diócesis que juren con la posible solemnidad la Constitución política de la monarquía, sirviéndose V.S., darme competente aviso de haberlo así ejecutado. ${ }^{26}$

L'objectiu era clar: el règim liberal no volia enemics del sistema dintre l'estructura eclesiàstica. Així que tot el clergat va haver de jurar la Constitució. I ho havien de fer perquè, si no, serien represaliats per incompliment de la llei. Veiem que existia un clar objectiu de depurar enemics dintre de l'estructura eclesiàstica. Josep Castellar ho expressa molt bé: «los que se atrevan a mancillar su Santa pureza con expresiones sediciosas, o por medio de la imprenta, serán castigados con toda la severidad prevenida en el código penal». ${ }^{27}$

Sabem que el clergat tarragoní va fer el jurament de dues maneres diferents. La primera fou un acte collectiu a la catedral i, després, de manera individual cada clergue va entregar al cap polític el jurament en forma escrita. La documentació expressa que la celebració collectiva es va celebrar al llarg de tot el dia 25 de març de

25 AHAT, Fons Secretaria de Cambra i Govern, subsèrie «Registres», «Oficis del general intendent i cap polític» (I8I9-I823), n. 9, f. 9 r

26 AHAT, Fons Secretaria de Cambra i Govern, subsèrie «Registres», «Oficis del general intendent i cap polític» (I8I9-I823), n. 9, f. $9 v$.

27 AHAT, Fons Secretaria de Cambra i Govern, subsèrie «Registres», "Oficis del general intendent i cap polític» (I8I9-I823), n. 9, f. $9 r$. 
I820. ${ }^{28} \mathrm{Al}$ matí, la celebració anava dirigida al clergat secular, tot el que hi va poder acudir, ja que els rectors de les poblacions més allunyades de Tarragona solament van jurar per escrit. A la tarda ho va fer el clergat regular dels convents. L'acte col-lectiu tenia la característica de ser una celebració litúrgica de portes obertes. Per tant, a l'acte no solament va assistir-hi el clergat, sinó també laics. Aquest fet és remarcable, ja que es va voler transmetre a la població de Tarragona que l'arquebisbat donava suport de manera pública a la Constitució. En aquest jurament va participar-hi tothom, no solament el clergat; és a dir, també els dirigents de l'arxidiòcesi, que, com s'ha esmentat, en aquell moment eren els vicaris generals. Després de l'acte col-lectiu va haver-hi l'obligatorietat de fer el jurament per escrit. Aquest fet és molt significatiu i va ser causat per dos motius. El primer és que no tots els clergues de l'arquebisbat podien assistir a l'acte collectiu, ja que l'extensió i la llunyania de la capital dificultaven la seva assistència. Per tant, l'única manera de jurar i que en quedés constància era mitjançant la correspondència. El segon motiu, i el més important, era la necessitat de preservar el jurament, ja que això ajudava a exercir el control de qui l'havia fet. I per aquest motiu tots els clergues que havien jurat la Constitució mitjançant l'acte colllectiu, després també van haver de fer-ho per escrit.

Els vicaris generals, un cop van rebre l'ofici del cap polític de fer jurar per escrit la Constitució als seus súbdits, van fer una circular que ordenava al clergat que havien de retornar-los una carta en la qual juraven la Constitució perquè posteriorment els vicaris la transmetessin al cap polític. Les correspondències van començar a arribar l'endemà de la celebració colllectiva a la catedral, el 26 de març. La primera fou del convent de franciscans de Tarragona, a causa de la pro-

28 Joan M. Quijada Bosch i Neus Sánchez Pié, Rebus Gestis Ecclesiae. Els llibres de notes del capitol de Tarragona (I734-I930), Barcelona, Fundació Noguera, 20I4, pp. 684-685. 
ximitat a la seu metropolitana. L'última de la qual hi ha constància a la documentació és la de la parròquia de Maspujols, el 24 de maig de $1820 .^{29}$

En aquest punt cal preguntar-se: quina fou la resposta del clergat davant aquesta ordre? És important analitzar bé aquesta resposta, ja que ens explicarà quina adhesió tenia el clergat tarragoní al nou sistema liberal. Hi ha un total de cinquanta-set correspondències jurades conservades, incloent-hi les de les parròquies i els convents. ${ }^{30}$ És important saber les parròquies que conformaven l'arquebisbat de Tarragona durant l'època d'estudi. El cens de parròquies més pròxim que hi ha, el tenim vint anys abans del Trienni, sota el pontificat de Francesc Armanyà. En el Llibre de registres del pontificat de fra Francesc Armanyà i Font (I8OI) veiem quina era la distribució territorial que hi havia. Segons el registre de l'arquebisbe Armanyà, l'arxidiòcesi estava dividida en dos partits: «El partido de Tarragona» $\mathrm{i}$ el «Vicariato foráneo de Montblanch y su partido». ${ }^{3 \mathrm{I}}$ El primer format per IOI poblacions i el segon grup format per 55 poblacions. Per tant, hi havia 156 parròquies, ja que segons fa constar l'arquebisbe Armanyà, «en ningún pueblo de este arzobispado hay más de una

29 Aquest fet pot ser rellevant o si més no curiós, ja que Tomàs Pedrol fou l'últim clergue del qual tenim constància que va fer el jurament escrit. Aquest clergue, com s'ha explicat, va desenvolupar un pensament liberal molt excepcional. Resulta interessant perquè no es detalla el motiu pel qual va trigar tant, però segurament el cap polític sabia quina adhesió tenia el rector de Maspujols al sistema constitucional i no hi ha cap documentació que pressioni Pedrol a fer el jurament, al contrari del que va passar amb altres rectors. Les declaracions jurades estan recopilades conjuntament a: AHAT, Fons Secretaria de Cambra i Govern, subsèrie «Registres», "Oficis del general intendent i cap polític» (I8I9-I823), n. 9, f. I3r-82r.

$30 \mathrm{Cal}$ ser curós amb les xifres, ja que actualment disposem de cinquanta-set correspondències jurades del clergat, però això no vol dir que en el moment d'enquadernar-les no n'hi hagués algunes que posteriorment s'han extraviat o bé s'han malmès.

3I AHAT, Arquebisbe, Pontificat de Francesc Armaña i Font, Llibre de registre del pontificat de fra Francesc Armaña i Font (І80I-I802), n. 96.

Cercles. Revista d'Història Cultural, 23 (2020), 57-79.

ISSN: 1139-0158. e-ISSN: 1699-7468. DOI: 10.1344/cercles2020.23.1010. 
parroquia». ${ }^{32}$ Durant el Trienni tenim aproximadament cent cinquanta-sis parròquies i cinquanta-set correspondències jurades. Per tant, sols va jurar la Constitució aproximadament un terç del total del clergat. Podem afirmar que hi hagué una baixa participació a jurar la Constitució, i ho podem constatar també perquè són moltes les correspondències del cap polític cap a l'arquebisbat dient que no s'està complint l'ordre.

De fet, les queixes de Josep Castellar no van trigar gaire a arribar. A principis d'abril ja hi ha una correspondència en la qual explica que ha rebut avisos que alguns individus del clergat secular i regular «olvidados de sus deberes procuran propagar especies autárquicas y contrarias a la unidad Nacional». ${ }^{33}$ El cap superior polític de la província de Catalunya els dona l'ordre de recordar «y hacer entender a todos sus súbitos» que anar en contra de la Constitució estava penat. Explica amb tots els ets i uts que "estoy procediendo con vigor a tomar todos los informes que puedan ponerse de manifiesto los autores y cómplices en tan grave delito, a fin de que sean castigados [...]». Deu dies després, el I3 d'abril, Josep Castellar demana als vicaris generals que l'informin «si algún individuo ha hecho este juramento con restricciones, protestas o reservas, a fin de que cumpla lo prevenido por el Rey en su Real Decreto de 26 de marzo último». ${ }^{34}$ Fer jurar la Constitució és una eina que ens permet saber quina adhesió tenia el clergat a la Constitució. I, tal com podem constatar, el suport al sistema constitucional ja inicialment fou molt baix: sols un terç del clergat va jurar la Constitució per escrit. A més a més, podem veure els esforços que va dedicar Josep Castellar a ordenar als

32 AHAT, Arquebisbe, Pontificat de Francesc Armaña i Font, Llibre de registre del pontificat de fra Francesc Armaña i Font (I80I-I802), n. 96, f. 310v.

33 AHAT, Fons Secretaria de Cambra i Govern, subsèrie «Registres», "Oficis del general intendent i cap polític» (I819-1823), n. 9, f. 83ri 83v.

34 AHAT, Fons Secretaria de Cambra i Govern, subsèrie «Registres», «Oficis del general intendent i cap polític» (I819-1823), n. 9, f. $96 r$. 
vicaris generals que tots ho havien de fer; si no, serien penats com a desobedients a la llei establerta.

\section{Constitució i altar: promoció de la Constitució des de l'altar}

Hem fet una radiografia de la ideologia predominant dintre del clergat de principis del Trienni, veient que la gran majoria va desobeir l'ordre de jurar la Constitució. Per què el règim liberal es va preocupar tant de controlar el clergat? Doncs perquè la influència de l'Església sobre la societat era molt gran; concretament, les idees difoses des de l'altar tenien un gran pes sobre l'opinió pública. D'aquest fet ja en foren conscients en aquell moment tant el cap polític com els clergues de l'arxidiòcesi tarragonina. En aquest apartat veurem com es va intentar obligar els rectors de les parròquies que no solament juressin la Constitució, sinó que l'expliquessin i en fessin promoció des de l'altar en les seves misses i litúrgies. Llavors, cal qüestionar-nos: en quin moment es va executar l'ordre que el clergat havia de defensar la Constitució des de l'altar? Quina fou l'estratègia del cap polític per fer complir aquesta ordre enfront d'un clergat que majoritàriament fou desobedient a les seves ordres?

Mitjançant la documentació veiem que va ser a partir del 27 d'abril de i820 que s'executà l'ordre de defensar la Constitució des de l'altar. ${ }^{35}$ Aquest dia, Josep Castellar va enviar una circular dirigida a tots els alcaldes constitucionals de Catalunya, la qual contenia transcrita la Reial ordren del Io de juny de I8I3, aprovada a les Corts de Cadis. Per tant, estem veient que l'ordre de promocionar la Constitució a les esglésies no va trigar gaire a arribar: sols un mes després de la seva proclamació. A més a més, veiem que la va executar empa-

35 AHAT, Fons Secretaria de Cambra i Govern, subsèrie "Registres», "Oficis del general intendent i cap polític» (I8I9-I823), n. 9, f. IIor-v i III $r$.

Cercles. Revista d'Història Cultural, 23 (2020), 57-79.

ISSN: 1139-0158. e-ISSN: 1699-7468. DOI: 10.1344/cercles2020.23.1010. 
rant-se en la Reial ordre aprovada set anys abans, durant la primera experiència constitucional del país (I8I2-I8I4). Aquesta Reial ordre de I8I3 explicava que

El amor y el respeto á los Soberanos, á la familia Real y al Gobierno es una obligación que dictan las leyes fundamentales del Estado [...]. De aquí proviene que los eclesiásticos, no solamente en sus sermones, egercicios espirituales y actos devotos deben infundir al pueblo estos principios. $^{36}$

És a dir, no solament havia d'haver-hi respecte i amor al rei, sinó també al govern, és a dir, al govern constitucional. És molt important recalcar que la circular anava dirigida als alcaldes, ja que era a aquests a qui es va encomanar la feina de controlar el rector de la parròquia de la població corresponent, de manera que eren ells els responsables de denunciar-ho. De fet, les últimes paraules de la circular advertien molt clarament que l'alcalde «será responsable de cualquiera infracción de esta ley no procediendo á las diligencias previas contra los transgresores, como cómplice por una tolerancia tan funesta á la causa nacional $[\ldots] »{ }^{37}$ Aquí cal fixar-se que Josep Castellar va optar per una altra estratègia per controlar el clergat. Aquest cop, l'ordre de controlar el clergat no va recaure directament sobre els vicaris generals. Això sí, els vicaris generals també n’eren responsables. El 3 de maig de $\mathrm{I}_{22 \mathrm{O}^{38}}$ Josep Castellar els va enviar una còpia de la circular que havia enviat als alcaldes i els advertia que

36 AHAT, Fons Secretaria de Cambra i Govern, subsèrie «Registres», «Oficis del general intendent i cap polític» (I819-I823), n. 9, f. IIor.

37 AHAT, Fons Secretaria de Cambra i Govern, subsèrie «Registres», «Oficis del general intendent i cap polític» (I819-I823), n. 9, f. III $r$.

38 AHAT, Fons Secretaria de Cambra i Govern, subsèrie «Registres», "Oficis del general intendent i cap polític» (I819-1823), n. 9, f. Io9r. 
també eren responsables de controlar els comportaments i la defensa de la Constitució per part dels seus súbdits religiosos.

Per tant, l'estratègia del cap polític d'afegir els alcaldes constitucionals a les tasques de control del clergat ens evidencia les dificultats que va tenir per fer complir l'ordre. Les queixes de Josep Castellar als vicaris generals no van trigar gaire. Un mes després que els vicaris fossin advertits que els clergues de l'arquebisbat havien d'explicar la Constitució, el io de juny va arribar la primera correspondència queixant-se dels rectors desobedients. El cap polític va ordenar que «se esplique la Constitución Política de la Monarquía, habiendo espedido al efecto un Real Decreto que he circulado, no era de esperar que fuese desoída su voz paternal por los ministros del Altar [...]». ${ }^{39}$ En les paraules veiem que hi havia un cert cansament de fer advertiments als clergues. Explica que molts havien normalitzat la vulneració de la llei. De fet, només divuit dies després d'aquest advertiment, en va arribar un altre. En aquest explica que «Son repetidas las quejas de algunos alcaldes constitucionales y de particulares de los pueblos sobre la inobservancia de algunos párrocos y vicarios en explicar la Constitución Política de la Monarquía en los días festivos según lo prevenido». ${ }^{40}$

En la correspondència del I7 d'octubre de 1820 veiem que la fiscalització del cap polític sobre els clergues va un pas més enllà. En aquesta carta s'ordena als vicaris generals que han d'advertir als seus súbdits que la defensa de la Constitució no solament s'ha de fer a l'altar, sinó que també en les seves converses privades s'han de cenyir a la llei establerta. És a dir, el cap polític adverteix als clergues que no conspirin contra la Constitució i no es posin en assumptes polítics. Tal com explica,

39 AHAT, Fons Secretaria de Cambra i Govern, subsèrie «Registres», "Oficis del general intendent i cap polític» (I8I9-I823), n. 9, f. II7r.

40 AHAT, Fons Secretaria de Cambra i Govern, subsèrie "Registres», "Oficis del general intendent i cap polític» (I819-1823), n. 9, f. I32r.

Cercles. Revista d'Història Cultural, 23 (2020), 57-79.

ISSN: 1139-0158. e-ISSN: 1699-7468. DOI: 10.1344/cercles2020.23.1010. 
[...] en otros actos religiosos y conversaciones familiares usen circunspección y decoro, que es el mejor ornato de la dignidad sacerdotal procurando no esparcir en las conciencias [...] especies contrarias a las leyes de justicia que nos rigen, ni turban el sosiego de las familias. ${ }^{4 \mathrm{I}}$

Alhora, cal analitzar també la postura que van tenir els vicaris generals a l'hora de fer complir les ordres del cap polític, ja que així podrem entendre com és que el cap polític, a mesura que el règim liberal anava consolidant-se i la tensió augmentava, va tenir una major preocupació per actuar-hi. Es va actuar sobre l'arquebisbat sempre amb l'objectiu de fer complir la llei per part dels clergues desobedients. Els vicaris generals van tenir un model de conducta que es basava a rebre les correspondències del cap polític i trametre una circular a tots els seus clergues, tant per jurar la Constitució com per anunciar que havien d'explicar la Constitució en les seves misses. Més enllà, veiem que no tingueren un paper actiu a castigar o apartar tots els clergues que havien desoït les ordres del cap polític. Per tant, podem afirmar que els vicaris generals van reaccionar d'una manera passiva, és a dir, no van oposar resistència al nou règim establert; però tampoc no van tenir una actitud activa per aconseguir que tot el clergat de l'arxidiòcesi jurés i promociones la Constitució des de l'altar.

\section{El zelador eclesiàstic: una intervenció directa}

Estem veient que, enfront de la dificultat que tingué el cap polític a fer complir la llei, hi va haver una major intervenció sobre l'estructura eclesiàstica. Aquest fet es va anar evidenciant a mesura que el

4I AHAT, Fons Secretaria de Cambra i Govern, subsèrie "Registres», "Oficis del general intendent i cap polític» (I819-I823), n. 9, f. I35r. 
context polític i social va ser més conflictiu. Molts dels opositors al règim liberal estaven dintre de l'estructura eclesiàstica, per això era totalment necessari poder intervenir d'una manera efectiva. Però, com estem veient, ho impedia la tasca realitzada mitjançant els vicaris generals. Per aquest motiu, el cap polític va decidir adoptar una nova estratègia. A partir del desembre de 1822 va decidir intervenir d'una manera més directa, estalviant-se la jerarquia eclesiàstica. Aquest fet és molt rellevant i insòlit fins al moment, perquè des de I820 fins a aquest moment les ordres eren transmeses pel cap polític als vicaris generals i eren executades per aquests últims. A partir del desembre de I822 el cap polític va crear el càrrec de zelador eclesiàstic. Aquests llocs foren ocupats per clergues reconeguts per la seva defensa del sistema liberal i estaven en contacte directe amb el cap polític. L'objectiu era que el zelador eclesiàstic fos l'encarregat d'executar les ordres del cap polític sobre la resta de clergues de l'arxidiòcesi. Per fer-ho possible, Jacobo Gil de Avalle va dissenyar una estratègia amb set directius. El Pla de Creació de Zeladors Eclesiàstics primerament fou enviat als vicaris generals i començava dient que:

Creyendo muy justo y conforme dar el correspondiente impulso para la pacificación, orden y tranquilidad de esta provincia por medio de eclesiásticos, virtuosos y adictos al sistema constitucional, he creído conveniente formar un plan que adjunto incluyo a V.S.S. ${ }^{42}$

En el primer punt del Pla el cap polític diu quins han de ser els clergues que poden ocupar aquest nou càrrec creat. Havien d' «estar dotados de aquellas luces que se requieren para desempeñar semejante encargo, hayan dado unas pruebas nada equivocas de haver sido siempre unos hombres verdaderamente adictos al sistema que

42 AHAT, Fons Secretaria de Cambra i Govern, subsèrie «Registres», "Oficis del general intendent i cap polític» (I8I9-I823), n. 9, f. 386 r.

Cercles. Revista d'Història Cultural, 23 (2020), 57-79.

ISSN: 1139-0158. e-ISSN: 1699-7468. DOI: 10.1344/cercles2020.23.1010. 
felizmente nos rige». En el segon article s'explica que dintre de la província de Tarragona hi haurà un zelador eclesiàstic a cada partit judicial. Els partits judicials eren una subdivisió política de les diputacions provincials. En aquesta divisió, la Diputació de Tarragona incloïa els partits judicials de Tarragona, Reus, Tortosa, Falset, Montblanc i Vilafranca. ${ }^{43}$

En el Pla s'explica que l'elecció dels clergues per a l'ocupació dels càrrecs l'havien de fer els vicaris generals. Aquest procediment resulta força important perquè ens demostra que el cap polític creà un càrrec d'enllaç entre l'estructura eclesiàstica i la civil, però reservà el dret d'elecció del zelador als vicaris generals. Però no fou un dret d'elecció totalment lliure, ja que, com s'ha explicat, els càrrecs havien de ser ocupats per clergues reconeguts per la seva defensa del liberalisme. A més a més, és molt interessant remarcar la correspondència del 7 de desembre de I822, ja que Jacobo Gil de Avalle va «recomanar» als vicaris que nomenessin Tomàs Pedrol zelador. Havia d'ocupar-se dels partits de Falset i Montblanc.

Quin fou el motiu per què el cap polític intervingués directament en l'elecció de Pedrol com a zelador? Doncs que tenia coneixença de la seva gran defensa del liberalisme. Dit en les seves pròpies paraules, el recomanava per la seva "conocida ilustración y sentimientos patrióticos». ${ }^{44}$ En la correspondència dels vicaris generals, escrita per Bonaventura Marès el dia 27 de desembre de I822, sabem quins foren els altres dos zeladors eclesiàstics de l'arquebisbat de Tarragona. Primerament, accepten la proposta de posar Pedroli el no-

43 L'historiador tarragoní Josep Adserà transcriu la llista de poblacions i partits judicials que integren la província de Tarragona l'any i822. José Adserà MarTorell, Tarragona capital de provincia. Estudio histórico documental sobre la división del territorio, Tarragona, Adserà, pp. I5I-I55.

44 AHAT, Fons Secretaria de Cambra i Govern, subsèrie «Registres», «Oficis del general intendent i cap polític» (I819-1823), n. 9, f. 386r. 
menen zelador de les partides de Reus i Montblanc. Després, elegeixen Francisco Caballé, regent de la parròquia de l'Argilaga, com a zelador de la partida de Tarragona. I Ramon Domènech, ecònom de la parròquia de Falset, com a zelador de la partida de Falset. ${ }^{45}$

Pel que fa a l'adhesió al sistema liberal, sabem de sobres que Tomàs Pedrol fou un clergue liberal. Sabem que, un cop va finalitzar el Trienni, sota el pontificat de Jaume Creus se li va obrir una causa al Tribunal Eclesiàstic, que el jutjava per les seves accions de defensa del nou règim constitucional. ${ }^{46}$ Després, la documentació ens revela que Francisco Caballé fou un clergue liberal obligat a fer exercicis espirituals un cop finalitzat el Trienni. ${ }^{47}$ Finalment, hem de reconèixer que tenim poques referències documentals sobre Ramon Domènech, però podem afirmar que també fou un clergue defensor de les idees liberals.

En l'article tercer del Pla, el cap polític comença a establir els poders que podien tenir dintre de l'arxidiòcesi els zeladors eclesiàstics. S'explica que a les parròquies situades a les capitals dels partits judicials i sempre que el lloc del rector de la població estigués vacant, el zelador eclesiàstic podia prendre el títol d'ecònom de la parròquia en propietat. Aquest fet és rellevant i serà comú en algunes de les parròquies de l'arxidiòcesi durant els últims anys del Trienni Liberal.

45 AHAT, Fons Secretaria de Cambra i Govern, subsèrie «Registres», "Oficis del general intendent i cap polític» (I819-I823), n. 9, f. 398 r.

46 AHAT, Processos del Tribunal Eclesiàstic, capsa 2, n. 20 bis, "Causa contra el rector de Maspujols (I824)».

47 Un cop finalitzat el Trienni Liberal, Jaume Creus, considerat enemic del règim liberal, va retornar a Tarragona per ocupar la mitra d'arquebisbe de l'arxidiòcesi. Durant el seu pontificat va voler represaliar els clergues que havien estat considerats liberals: havien de fer una sèrie d'exercicis espirituals. En temps present tenim conservada una llista de tots els clergues considerats liberals, entre els quals consten Tomàs Pedrol i Francesc Caballé. Vegeu AHAT, Arquebisbe, Pontificat Jaume Creus i Martí, capsa I3, n. zoe.

Cercles. Revista d'Història Cultural, 23 (2020), 57-79.

ISSN: 1139-0158. e-ISSN: 1699-7468. DOI: 10.1344/cercles2020.23.1010. 
A partir de la documentació trobem diversos casos de rectors que abandonen la parròquia per anar a combatre amb les partides absolutistes. ${ }^{4}$

En l'article quart del Pla es pot veure quin era l'objectiu del cap polític: no volia que hi hagués cap rector considerat absolutista en cap ciutat capital de partit judicial. En cas que aquest rector fos considerat absolutista, havia de ser substituitt per un altre rector liberal. Aquesta decisió del cap polític mostra quina preocupació va tenir per controlar les parròquies situades en grans poblacions. Segurament el desig era tenir controlats tots els rectors de totes les poblacions de l'arxidiòcesi, però, arribats a l'any I 822 i veient l'oposició que hi havia a les ordres del cap polític, era controlar les parròquies importants. L'article següent també ens mostra aquest esforç, ja que no solament es parla de tenir controlades les parròquies capitals de partits judicials, sinó també les capitals de diòcesi, en aquest cas, Tortosa i Tarragona. ${ }^{49}$ En el cas d'aquestes poblacions, els zeladors eclesiàstics eren els vicaris capitulars, ${ }^{50}$ ja que la parròquia que ocupa la capitalitat és la catedral. En cas que això no fos possible perquè els vicaris no reunissin les qualitats requerides, el càrrec seria ocupat pel capellà més antic de la ciutat, i si aquest no pogués, seria ocupat per algun rector d'alguna població del mateix partit judicial, però sempre amb la condició que havia de ser addicte al sistema constitucional.

48 Aquest fet, no solament en la documentació de l'arxidiòcesi de Tarragona. A la zona del Penedès, Ramon Arnabat també explica aquests aixecaments absolutistes dels rectors del territori. Ramon ARnabat Mata, Liberals i reialistes: el trienni liberal al Penedès (I820-I823), Alguaire, Ajuntament d'Alguaire, I997.

49 Cal tenir en compte que la divisió religiosa no es regeix de la mateixa manera que la divisió política. Per tant, la divisió política queda emmarcada per la divisió provincial, la Diputació de Tarragona, i per la subdivisió, els partits judicials. D’altra banda, la divisió religiosa queda dividida amb els bisbats: el bisbat de Tortosa i l'arquebisbat de Tarragona.

50 Dintre de la religió catòlica, el vicari capitular és com el rector d'una parròquia, però de la catedral. És a dir, és la màxima autoritat religiosa de la catedral. Exerceix els mateixos drets que un bisbe o arquebisbe, però sense gaudir de l'ordenació episcopal. 
Arribats a aquest punt, sabem els poders que tenien els zeladors eclesiàstics, però quina era la feina que havien de desenvolupar? En el sisè i el setè articles s'estipulen les tasques que havien d'executar els zeladors eclesiàstics. En el sisè article queda constància que la tasca dels zeladors eclesiàstics era explicar a la resta de clergues d'aquell partit, l'obligatorietat i els beneficis de donar suport al sistema constitucional. Després, en el setè article s'explica que els zeladors eclesiàstics havien d'informar cada mes sobre algunes qüestions directament al cap polític, i també als vicaris generals. En aquest informe mensual s'havia de fer constar

[...] los adelantamientos que vayan haciendo en sus respectivos distritos, y al mismo tiempo de aquellos párrocos que más se hayan distinguido en el particular; así como de todos aquellos, que hayan sido resistentes en dicha obligación, o que por falta de luces y conocimientos políticos no sean aptos para desempeñar su ministerio. ${ }^{\text {II }}$

A partir d'aquest punt, el control del clergat per a la defensa de la Constitució canvia. Els vicaris generals deixen de ser els encarregats principals i són rellevats pels zeladors eclesiàstics. Aquest nou càrrec creat pel cap polític permetia assegurar-se que farien aquest control clergues addictes al règim liberal. Aquest pas és molt rellevant per diversos motius: en primer lloc, perquè mostra que part de la desobediència venia de la poca implicació dels vicaris a fer obeir les ordres als seus súbdits; després, perquè això significava que el cap polític s'introduïa plenament en l'òrgan religiós. Veiem, doncs, que es va promocionar com a zeladors eclesiàstics els sacerdots més addictes al sistema liberal. Persones de confiança de dintre del clergat que realitzaven un informe mensual que anava a parar directament al cap polític.

5I AHAT, Fons Secretaria de Cambra i Govern, subsèrie «Registres», "Oficis del general intendent i cap polític» (I8I9-I823), n. 9, f. $387 v$.

Cercles. Revista d'Història Cultural, 23 (2020), 57-79.

ISSN: 1139-0158. e-ISSN: 1699-7468. DOI: 10.1344/cercles2020.23.1010. 


\section{Conclusió}

Per primer cop i mitjançant la documentació, podem demostrar que la fiscalització del comportament del clergat sobre l'altar fou fonamental en les tasques realitzades pel cap polític. Amb aquesta recerca es vol afirmar clarament que des del primer dia del Trienni Liberal va haver-hi una necessitat de controlar les idees que es difonien des dels altars de totes les parròquies de l'arxidiòcesi. Els poders civils foren conscients que la supervivència del règim polític constitucional depenia del suport de l'estructura eclesiàstica. Però quin fou el principal problema per al cap polític? Hem vist que la major part del clergat de l'arxidiòcesi de Tarragona no va estar disposat a colllaborar amb el règim liberal. Dintre del clergat hi havia un predomini dels que rebutjaven el sistema liberal, atès que sols un terç va jurar la Constitució. Però aquesta sols era la situació de partença.

El temps del Trienni va anar passant, les dificultats i bel.ligeràncies van anar creixent, i gran part del clergat va continuar desobeint les ordres de promocionar la Constitució des de l'altar. A més a més, els vicaris no participaren activament per fer acomplir aquestes ordres, sinó que van intentar sobreviure sense ser represaliats, alhora que van evitar colllaborar activament en la defensa de la Constitució. Amb tot això, ens trobem amb el cap polític cada cop més preocupat per trobar una fórmula per controlar d'una millor manera el clergat i aproximar-lo al liberalisme.

Com s'ha dit, controlar el clergat era fonamental. Els rectors tenien un pes important sobre l'opinió pública i no existiria consolidació total del liberalisme sense la defensa de la Constitució des dels altars. És en aquest punt que arribem al desembre de I822. La creació del càrrec de zelador eclesiàstic fou molt important perquè ens mostra la poca confiança que tenia el cap polític en els vicaris generals. Però aquesta intervenció més directa sobre l'estructura eclesiàstica sols fou possible gràcies al suport intern dels clergues liberals. 